\title{
ASUHAN KEPERAWATAN PADA PASIEN GAGAL GINJAL KRONIS DENGAN HIPERTENSI PRE-HD DENGAN MENGGUNAKAN PENERAPAN TERAPI MUSIK KLASIK
}

\author{
Nursing Care In Chronic Renal Failure Patients With Pre-Hd Hypertension Using \\ Application Of Classical Music Therapy
}

Sinta Wijayanti

STIKes Panca Bhakti

*Email korespondensi : sinta.wija.wijayanti@gmail.com

\begin{abstract}
Abstrak
Pendahuluan : Gagal ginjal kronik (GGK) merupakan tahap akhir kegagalan nefron untuk mempertahankan fungsinya akibat destruksi progresif nefron yang bersifat irreversible dan membutuhkan terapi pengganti ginjal yaitu hemodialisis. Hemodialisis merupakan suatu terapi yang digunakan ketika ginjal tidak mampu melaksanakan fungsinya untuk mengeluarkan toksik uremik, mengatur cairan elektrolit tubuh, dan memiliki komplikasi hipertensi. Pada pasien hemodialisis, hipertensi yang tidak terkontrol dapat meningkatkan prevalensi penyakit kardiovaskular sehingga merupakan faktor yang sangat penting pada prognosis terjadinya komplikasi kardiovaskular pada pasien gagal ginjal kronis dengan hipertensi. Banyak terapi non farmakologis yang telah dikembangkan dalam dunia keperawatan salah satunya terapi musik klasik. Tujuan dari terapi ini untuk mengidentifikasi dan menganalisa tekanan darah pasien pre-hd sebelum dan sesudah diberikan terapi musik klasik. Metode : Desain penelitian ini menggunakan metode pendekatan Applied Research selama 1 kali sehari selama 6 hari. Jumlah sampel yang diambil adalah 10 sampel yang sesuai dengan kriteria inklusi. Instrumen dalam penelitian ini menggunakan adalah MP3 Player, musik klasik Mozart, headphone, lembar observasi sphygnomanometer clock, dan stetoskop. Hasil : Berdasarkan penelitian terdapat penurunan tekanan darah pada kesepuluh responden setelah dilakukan terapi musik klasik selama 15 menit. Setelah dilakukan terapi musik klasik selama 15 menit, kesepuluh responden mengalami penurunan tekanan darah dengan rata-rata sistolik $17,2 \mathrm{mmHg}$ dan diastolik 7,5 mmHg. Kesimpulan : Hasil penelitian ini adalah pemberian terapi musik klasik dapat menurunkan tekanan darah pada pasien gagal ginjal kronik.
\end{abstract}

Kata kunci: Gagal Ginjal Kronis; Hipertensi Pre-Hemodialisis; Terapi musik klasik.

\begin{abstract}
Introduction: Chronic renal failure (CKD) is the final stage of nephron failure to maintain its function due to progressive nephron destruction which is irreversible and requires renal replacement therapy, namely hemodialysis. Hemodialysis is a therapy used when the kidneys are unable to carry out their functions to excrete uremic toxins, regulate body electrolytes, and have hypertension complications. In hemodialysis patients, uncontrolled hypertension can increase the prevalence of cardiovascular disease so that it is a very important factor in the prognosis of cardiovascular complications in chronic renal failure patients with hypertension. Many nonpharmacological therapies have been developed in the world of nursing, one of which is classical music therapy. The purpose of this therapy is to identify and analyze the blood pressure of pre-HD patients before and after being given classical music therapy. Methods: The design of this study used the Applied Research approach for 1 time a day for 6 days. The number of samples taken was 10 samples that matched the inclusion criteria. The instruments in this study were MP3 Player, Mozart classical music, headphones, sphygnomanometer clock observation sheet, and a stethoscope. Results: Based on the research, there was a decrease in blood pressure in the ten respondents after classical music therapy was performed for 15 minutes. After 15 minutes of classical music therapy, the ten respondents experienced a decrease in blood pressure with an average systolic of $17.2 \mathrm{mmHg}$ and a diastolic of $7.5 \mathrm{mmHg}$. Conclusion: The result of this study is that classical music therapy can reduce blood pressure in patients with chronic kidney failure.
\end{abstract}

Keywords: Chronic Kidney Failure; Pre-Hemodialysis Hypertension; Classical music therapy 


\section{Pendahuluan}

Gagal ginjal kronik (GGK) merupakan tahap akhir kegagalan nefron untuk mempertahankan fungsinya akibat destruksi progresif nefron yang bersifat irreversible. Destruksi nefron menyebabkan gangguan fungsi filtrasi, reabsorbsi, sekresi dan ekskresi sehingga ginjal tidak mampu mengeluarkan hasil sisa metabolisme tubuh, mengonsentrasikan urine, serta mengatur pengeluaran cairan-elektrolit, dan akhirnya mempengaruhi seluruh fungsi sistem tubuh ${ }^{123}$. Pada penyakit GGK terjadi kerusakan massa nefron sebesar $90 \%$ sehingga menyebabkan penurunan Laju Filtrasi Glomerulus (LFG) $<15 \mathrm{ml} /$ menit $^{2}$. Penurunan LFG menyebabkan tubuh tidak mampu melaksanakan proses pengeluaran cairan dan produk limbah sehingga membutuhkan Terapi Pengganti Ginjal (TPG). Terdapat tiga metode TPG yaitu Hemodialisis Continuous Ambulatory Peritoneal Dialysis (CAPD), dan transplantasi ginjal ${ }^{4}$.

Persentase prevalensi hemodialisis di dunia dari tahun 2011 sampai tahun 2015 semakin meningkat jumlahnya yaitu sebanyak 54\% sampai $69 \%{ }^{5}$. Di Indonesia terdapat 11.689 pasien yang aktif menjalani hemodialisis pada tahun 2014 dan terjadi peningkatan sebanyak 30.554 orang pada tahun 2015. Secara keseluruhan terjadi peningkatan sebanyak 18.865 pasien yang aktif menjalani hemodialisis sampai akhir tahun 2015 pada 249 unit hemodialisis di Indonesia ${ }^{1}$.

Menurut Indonesia Renal Registry, (2018) di Lampung, terdapat 23 unit HD salah satunya Klinik Hemodialisis Lions. Klinik Hemodialisis Lions terletak di Bandar Lampung. Pada data 2020 insidensi populasi gagal ginjal kronik yang menjalani hemodialisis di Klinik Hemodialisa Lions Bandar Lampung dalam 6 bulan terakhir yaitu berjumlah 60 pasien dalam menjalani hemodialisis di Klinik Hemodialisa Lions ${ }^{6}$.

Pasien hemodialisis ada yang tidak lama bertahan hidup, namun ada juga yang bertahan hingga bertahun-tahun dengan menjalani hemodialisis 6 . Sekitar $60 \%$ sampai $80 \%$ pasien hemodialisis meninggal karena kelebihan cairan $^{7}$. Kelebihan cairan pada pasien HD dapat menimbulkan komplikasi lanjut seperti hipertensi, aritmia, efusi perikardial, gagal jantung, serta edema pulmonal, efusi pleura, dan sesak nafas ${ }^{8}$.

Hipertensi atau tekanan darah tinggi sering kali muncul tanpa gejala, sehingga disebut sebagai the silent killer atau sering disebut sebagai, pembunuh diam-diam. Secara global tingkat pravalensi hipertensi diseluruh dunia masih tinggi. Lebih dari seperempat jumlah populasi dunia saat ini menderita hipertensi. Kerusakan yang disebabkan dari hipertensi dapat berakibat fatal yang menimbulkan komplikasi berupa serangan jantung, stroke, perdarahan dan gangguan ginjal $^{9}$

Pada pasien GGK-HD, hipertensi yang tidak terkontrol dapat meningkatkan prevalensi penyakit kardiovaskular sehingga merupakan faktor yang sangat penting pada prognosis terjadinya komplikasi kardiovaskular pada GGK-HD. Komplikasi pada penderita ini merupakan penyebab utama kardiovaskular pada penderita ini merupakan penyebab utama mortalitas dan morbiditaspada GGK-HD ${ }^{7}$.

Hipertensi merupakan salah satu faktor pemicu terjadinya penyakit ginjal akut, penyakit ginjal kronis, hingga gagal ginjal. Sebaliknya, saat fungsi ginjal mengalami gangguan maka tekanan darah akan meningkat dan dapat menimbulkan hipertensi ${ }^{8}$. Beberapa penelitian memberikan bukti bahwa penurunan tekanan darah memberikan keuntungan mengurangi kerusakan organ target atau mengurangi progresivitas penyakit ginjal ${ }^{10}$.

Peran perawat dalam penanganan hipertensi Pra-hemodialisis perlu dilakukan penatalaksanaan penyakit hipertensi, baik secara terapi farmakologi maupun non farmakologi. Pada terapi farmakologi beberapa obat golongan beta - blocker dapat menimbulkan efek samping ${ }^{10}$. Sejauh penggunaan obat farmakologi memberikan efek samping perlu di upayakan penatalaksanaan 
secara non farmakologi seperti mengatur pola hidup sehat dan merubah gaya hidup serta menciptakan keadaan rileks dapat dilakukan seperti terapi musik klasik, terapi relaksasi otot progresif, terapi relaksasi nafas dalam, dan hipnoterapi ${ }^{6}$.

Di Indonesia, terapi musik sangat populer untuk bidang kesehatan, terutama untuk penurunan tekanan darah. Kementrian Kesehatan Republik Indonesia tahun 2016 menjelaskan bahwa dibutuhkan upaya bersama untuk menyadarkan masyarakat agar senantiasa melindungi diri dan keluarga dari Penyakit Tidak Menular (PTM) dengan cara membiarkan berprilaku CERDIK, yaitu cek kesehatan secara berkala, enyahkan asap rokok, rajin aktivitas fisik, diet sehat dan seimbang, istirahat cukup, dan kelola stress. Pada program kemenkes tersebut, salah satu menekan atau mencegah bahaya hipertensi atau penyakit tidak menular adalah mengelola stress yaitu dapat dilakukan dengan melakukan terapi suara, seperti mendengarkan musik (Kemenkes, 2016).

Musik merupakan sebuah rangsangan pendengaran yang terorganisir yang terdiri atas melodi, ritme, harmoni, timbre, bentuk dan gaya. Musik klasik seringkali menjadi acuan terapi musik karena memiliki rentan nada yang luas dan tempo yang dinamis ${ }^{9}$. Sebuah penelitian yang dipresentasikan pada konfrensi tahunan ke-62 American Heart Association 2008, mengemukakan bahwa mendengarkan bahwa mendengarkan musik klasik bisa menurunkan tekanan darah penderita hipertensi ${ }^{8}$. Berdasarkan lingkup latar belakang diatas, penulis tertarik untuk mengadakan penelitian mengenai pengaruh musik klasik terhadap penurunan tekanan darah pada pasien pre-hemodialisa di Klinik Hemodialisis Lions Bandar Lampung.

\section{Metode}

Penelitian ini merupakan penelitian deskriptif dengan menggunakan metode pendekatan studi kasus. Pendekatan studi kasus ini bertujuan untuk mengetahui dampak pemberian terapi musik klasik pada penurunan hipertensi prehemodialisis di Klinik Hemodialisis Lions Bandar Lampung. Respoden dalam penelitian ini berjumlah 10 orang responden sesuai kriteria inklusi dan eksklusi. Instrumen yang digunakan dalam penelitian ini adalah MP3 Player, musik klasik Mozart yang berjudul Eline Kleine Nacht musik, K. 525: I. Allegro, headphone, lembar observasi sphygnomanometer clock, dan stetoskop. Pengumpulan data dikumpulkan dari hasil WOD (wawancara, observasi, dokumen). Hasil ditulis dalam bentuk catatan lapangan, kemudian disalin dalam bentuk transkrip (catatan terstruktur). Penerapan terapi musik klasik diberikan 1 kali selama 6 hari. Etika dalam penelitian ini yaitu prinsip Benefience, prinsip Menghargai Martabat Manusia (Respect Human For Dignity), dan prinsip keadilan

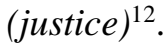

\section{Hasil}

Tabel 1 Pengukuran Tekanan Darah Sebelum Dilakukan Terapi Musik Klasik pada Pasien Hipertensi Pre-HD di Klinik Hemodialisa Lions Bandar Lampung

\begin{tabular}{ccc}
\hline No & Nama & Tekanan darah \\
\hline 1 & Tn. R & $170 / 80 \mathrm{mmHg}$ \\
2 & Tn B & $170 / 85 \mathrm{mmHg}$ \\
3 & Ny. W & $155 / 67 \mathrm{mmHg}$ \\
4 & Ny. S & $170 / 70 \mathrm{mmHg}$ \\
5 & Tn. L & $165 / 67 \mathrm{mmHg}$ \\
6 & Tn. H & $187 / 84 \mathrm{mmHg}$ \\
7 & Tn. J & $165 / 67 \mathrm{mmHg}$ \\
8 & Ny. T & $187 / 86 \mathrm{mmHg}$ \\
9 & Ny. E & $165 / 97 \mathrm{mmHg}$ \\
10 & Ny. M & $170 / 75 \mathrm{mmHg}$ \\
\hline
\end{tabular}

Berdasarkan tabel diatas dapat terlihat tekanan darah klien sebelum dilakukan tindakan terapi musik klasik yaitu, pada pasien Tn.R tekanan darahnya $170 / 80 \mathrm{mmHg}$, pada pasien $\mathrm{Tn}$. B tekanan darahnya $170 / 85 \mathrm{mmHg}$, pada pasien Ny. W tekanan darahnya $155 / 67 \mathrm{mmHg}$, pada pasien Ny. S tekanan darahnya 170/70 $\mathrm{mmHg}$, pada pasien Tn. L tekanan darahnya 165/67 $\mathrm{mmHg}$, pada pasien $\mathrm{Tn}$. H tekanan darahnya 187/84 mmHg, pada pasien Tn. J tekanan darahnya $165 / 67 \mathrm{mmHg}$, pada pasien ke 8 yaitu Ny. T tekanan darahnya $187 / 86 \mathrm{mmHg}$, pada pasien ke 9 yaitu $\mathrm{Ny}$. E tekanan darahnya 165/97 mmHg, pada pasien ke 10 yaitu $\mathrm{Ny}$. M tekanan darahnya $170 / 75 \mathrm{mmHg}$. 
Tabel 2 Pengukuran Tekanan Darah Setelah Dilakukan Terapi Musik Klasik Pada Pasien Hipertensi Pre-HD Klinik Hemodialisa Lions Bandar Lampung

\begin{tabular}{ccc}
\hline No & Nama & Tekanan darah \\
1 & Tn. R & $158 / 75 \mathrm{mmHg}$ \\
2 & Tn. B & $160 / 80 \mathrm{mmHg}$ \\
3 & Ny. W & $136 / 87 \mathrm{mmHg}$ \\
4 & Ny. S & $148 / 70 \mathrm{mmHg}$ \\
5 & Tn. L & $150 / 75 \mathrm{mmHg}$ \\
6 & Tn. H & $152 / 80 \mathrm{mmHg}$ \\
7 & Tn. J & $155 / 70 \mathrm{mmHg}$ \\
8 & Ny. T & $160 / 72 \mathrm{mmHg}$ \\
9 & Ny. E & $155 / 80 \mathrm{mmHg}$ \\
10 & Ny. M & $158 / 70 \mathrm{mmHg}$ \\
\hline
\end{tabular}

Berdasarkan tabel 2 dapat terlihat tekanan darah klien setelah dilakukan tindakan terapi musik klasik yaitu pada pasien $\mathrm{Tn}$. R tekanan darahnya menurun menjadi $158 / 75 \mathrm{mmHg}$, pada pasien Tn. B tekanan darahnya menurun menjadi $160 / 80 \mathrm{mmHg}$, pada pasien $\mathrm{Ny}$. W tekanan darahnya menurun menjadi $136 / 87 \mathrm{mmHg}$, pada pasien Ny. S tekanan darahnya 148/70 mmHg, pada pasien Tn. L tekanan darahnya $150 / 75 \mathrm{mmHg}$, pada pasien $\mathrm{Tn}$. $\mathrm{H}$ tekanan darahnya 152/80 $\mathrm{mmHg}$, pada pasien Tn. J tekanan darahnya $155 / 70 \mathrm{mmHg}$, pada pasien Ny. T tekanan darahnya $160 / 72 \mathrm{mmHg}$, pada pasien Ny. E tekanan darahnya 155/80 mmHg, dan pada pasien $\mathrm{Ny}$. M tekanan darahnya 158/70 mmHg.

Tabel 3 Rata-rata Tekanan Darah Sesudah Dilakukan Terapi Musik klasik Pada Pasien Hipertensi Pre-HD

\begin{tabular}{cccc}
\hline No & Nama & $\begin{array}{c}\text { Rata rata } \\
\text { tekanan } \\
\text { darah } \\
\text { (sistolik) }\end{array}$ & $\begin{array}{c}\text { Rata rata } \\
\text { tekanan } \\
\text { darah } \\
\text { (diastolik) }\end{array}$ \\
\hline 1 & Tn. R & $12 \mathrm{mmHg}$ & $5 \mathrm{mmHg}$ \\
2 & Tn B & $10 \mathrm{mmHg}$ & $5 \mathrm{mmHg}$ \\
3 & Ny. W & $19 \mathrm{mmHg}$ & $20 \mathrm{mmHg}$ \\
4 & Ny. S & $22 \mathrm{mmHg}$ & $0 \mathrm{mmHg}$ \\
5 & Tn. L & $15 \mathrm{mmHg}$ & $8 \mathrm{mmHg}$ \\
6 & Tn. H & $35 \mathrm{mmHg}$ & $4 \mathrm{mmHg}$ \\
7 & Tn. J & $10 \mathrm{mmHg}$ & $3 \mathrm{mmHg}$ \\
8 & Ny. T & $27 \mathrm{mmHg}$ & $14 \mathrm{mmHg}$ \\
9 & $\mathrm{Ny} . \mathrm{E}$ & $10 \mathrm{mmHg}$ & $11 \mathrm{mmHg}$ \\
10 & $\mathrm{Ny} . \mathrm{M}$ & $12 \mathrm{mmHg}$ & $5 \mathrm{mmHg}$ \\
\hline \multicolumn{2}{l}{ Rata-rata } & $17,2 \mathrm{mmHg}$ & $7,5 \mathrm{mmHg}$ \\
\hline
\end{tabular}

Berdasarkan hasil penelitian yang di mulai dari tanggal $1-6$ Juni 2020, didapatkan rata-rata penurunan tekanan darah diastolik 10 orang responden yaitu $17,2 \mathrm{mmHg}$ dan sistolik yaitu 7,5 $\mathrm{mmHg}$.

Tabel 4 Kategori Hipertensi Sebelum dan Sesudah Terapi Musik klasik pada Pasien Hipertensi Pre-HD

\begin{tabular}{cccc}
\hline No & Nama & $\begin{array}{c}\text { Kategori } \\
\text { Hipertensi } \\
\text { Sebelum } \\
\text { Intervensi }\end{array}$ & $\begin{array}{c}\text { Kategori } \\
\text { Hipertensi } \\
\text { Sesudah } \\
\text { Intervensi }\end{array}$ \\
\hline 1 & Tn. R & Sedang & Ringan \\
\hline 2 & Tn B & Sedang & Sedang \\
\hline 3 & Ny. W & Ringan & Normal \\
\hline 4 & Ny. S & Sedang & Ringan \\
\hline 5 & Tn. L & Sedang & Ringan \\
\hline 6 & Tn. H & Berat & Ringan \\
\hline 7 & Tn. J & Sedang & Ringan \\
\hline 8 & Ny. T & Berat & Sedan \\
\hline 9 & Ny. E & Sedang & Ringan \\
\hline 10 & Ny. M & Sedang & Ringan \\
\hline
\end{tabular}

Berdasarkan ketegori hipertensi pada kesepuluh responden, diketahui Tn.R masuk dalam kategori hipertensi sedang, setelah diberikan musik klasik menjadi kategori hipertensi ringan, pada Tn. B masuk dalam kategori hipertensi sedang, setelah diberikan musik klasik menjadi kategori hipertensi sedang, pada $\mathrm{Ny}$. W masuk dalam kategori hipertensi ringan, setelah diberikan musik menjadi kategori hipertensi normal tinggi, pada $\mathrm{Ny}$. S masuk dalam kategori hipertensi sedang, setelah diberikan musik klasik menjadi kategori hipertensi ringan, pada Tn. L masuk dalam kategori hipertensi sedang, setelah diberikan musik klasik menjadi kategori hipertensi ringan, pada Tn. H masuk dalam kategori hipertensi berat, setelah diberikan musik klasik menjadi kategori hipertensi ringan, pada Tn. J masuk dalam kategori hipertensi sedang, setelah diberikan musik klasik menjadi kategori hipertensi ringan, pada $\mathrm{Ny}$. $\mathrm{T}$ masuk dalam kategori hipertensi berat, setelah diberikan musik klasik menjadi kategori hipertensi sedang, pada Ny. E masuk dalam kategori hipertensi sedang, setelah diberikan musik klasik menjadi kategori hipertensi ringan, pada Ny. M masuk dalam kategori hipertensi sedang, 
setelah diberikan musik klasik menjadi kategori hipertensi ringan.

\section{Pembahasan}

Berdasarkan hasil penelitian yang di mulai dari tanggal 1 - 6 Juni 2020, setelah di lakukan terapi musik klasik selama 15 menit pada pasien hipertensi pre-HD mengalami penurunan tekanan darah. Hal ini sesuai dengan Nurrahmani (2012) bahwa dengan mendengarkan musik klasik sekitar 10 s.d. 30 menit dengan tempo yang lambat (60 s.d. 80 bpm) per hari, dapat memberikan banyak manfaat bagi tubuh. Musik klasik dapat mengubah secara efektif ambang otak yang dalam keadaan stres menjadi lebih rileks, karena musik secara mudah dapat diterima oleh organ pendengaran dan mudah ditangkap oleh otak. Musik klasik juga dapat mengaktivasi sistem limbik yang mengatur emosi seseorang menjadi lebih rileks yang mengakibatkan pembuluh darah berdilatasi sehingga dapat menurunkan tekanan darah.

Berdasarkan hasil penelitian diketahui hasil rata-rata penurunan tekanan darah diastolik 10 orang responden yaitu $17,2 \mathrm{mmHg}$ dan sistolik yaitu $7,5 \mathrm{mmHg}$, yang pada awalnya rata-rata tekanan darah responden dalam kategori hipertensi sedang menjadi dalam kategori hipertesi ringan. Hal tersebut sesuai dengan jurnal penelitian yang dilakukan oleh Zanini, (2009) mengatakan bahwa terapi musik klasik ini dapat berkontribusi pada pengontrolan tekanan darah pasien dan dapat digunakan dalam program perawatan multidisiplin pasien hipertensimenurunkan tekanan darah pasien.

Lebih lanjut dalam penelitian Serayar et al (2013), yang dilakukan di RSUP. PROF.Dr. Kandou Manado bahwa 30 orang pasien dengan hipertensi pre-HD yang mendapat terapi musik klasik terlihat adanya perubahan tekanan darah secara signifikan pada kelompok eksperimen dengan intervensi mendengarkan musik klasik $p$ value $=0,00(<\mathrm{a}=0,05)$ untuk kelompok eksperimen dengan intervensi musik klasik, sedangkan untuk kelompok kontrol didapatkan nilai $p$ value $=1,00(>a=0,5)$. Dari hasil penelitian ini didapatkan hasil perubahan tekanan darah pada kesepuluh responden terjadi penurunan tekanan darah yang signifikan. Maka peneliti berpendapat bahwa pemberian terapi musik klasik dalam menurunkan tekanan darah efektif dalam menurunkan tekanan darah.

Hasil penelitian ini juga menunjukkan terdapat satu orang responden yaitu reponden ke- $2 \mathrm{Tn}$.B menunjukkan terjadi penurunan hasil tekanan darah setelah diberikan terapi musik klasik. Pada responden ke-2 ini setelah di kategorikan berdasarkan kategori hipertensi menunjukkan tekanan darah sebelum dan sesudah pemberian terapi pada responden tersebut berada dalam kategori hipertensi sedang. Hal ini dapat terjadi karena saat pemberian intervensi responden tidak relaks dan tampak tegang sehingga kurang berkonsentrasi saat diberikan intervensi.

\section{Kesimpulan}

Berdasarkan penelitian terdapat pengaruh terhadap penurunan tekanan darah pada kesepuluh responden di Klinik Hemodialisa Lions Bandar Lampung setelah dilakukan terapi musik klasik selama 15 menit. Tekanan darah kesepuluh responden sebelum dilakukan terapi musik klasik berada di rentan hipertensi ringan yaitu sistolik 140-159 mmHg dan diastolik 90$99 \mathrm{mmHg}$, hipertensi sedang yaitu sistolik 160$179 \mathrm{mmHg}$ dan diastolik $100-109 \mathrm{mmHg}$ dan hipertensi berat yaitu sistolik 180-209 dan diastolik 110-119 mmHg. Setelah dilakukan terapi musik klasik selama 15 menit, kesepuluh responden mengalami penurunan tekanan darah dengan rata-rata sistolik $17,2 \mathrm{mmHg}$ dan diastolik 7,5 $\mathrm{mmHg}$.

\section{Ucapan Terima Kasih}

Ucapan terima kasih penulis haturkan kepada STIKes Panca Bhakti dan semua pihan yang telah membantu proses penelitian ini dari awal sampai selesai.

\section{Daftar Pustaka}

1. National Kidney Foundation. NKF KDOQI clinical practice guidelines [Internet]. 2019 [cited 2019 Jan 19]. Available from: https://www.kidney.org/professionals/gui delines

2. Price SA, Wilson LM. Patofisiologi: Konsep Klinis Proses-Proses Penyakit. 
Jakarta: EGC; 2012.

3. Black J, Hawks J. Keperawatan Medikal Bedah: Manajemen Klinis untuk Hasil yang Diharapkan. Jakarta: EGC; 2014.

4. Smeltzer S, Bare B. Keperawatan Medikal Bedah. 8th ed. Jakarta: EGC; 2013.

5. United States Renal Data System. 2017 USRDS annual data report: Epidemiology of kidney disease in the United States. Volume 2: End-Stage Renal Disease in the United States. Chapter 1: Incidence, Prevalence, Patient Characteristics, and Treatment Modalities. 2017;2:247-76.

6. Saran R, Robinson B, Abbott KC, Agodoa LYC, Bragg-Gresham J, Balkrishnan R, et al. US Renal Data System 2018 Annual Data Report: Epidemiology of Kidney Disease in the United States. Am J Kidney Dis [Internet]. 2019 Mar;73(3):A7-8. Available from: https://linkinghub.elsevier.com/retrieve/pi i/S0272638619300095

7. Herawati N, Sari KM, Murtiningsih AT. Pengaruh Terapi Musik Klasik Terhadap Penurunan Tekanan Darah Pada Lansia Dengan Hipertensi Di Kelurahan Simpang Rumbio Wilayah Kerja Puskesmas Ktk Kota Solok. J Penelit dan Kaji Ilm Menara Ilmu. 2018;XII(3):72-9.

8. Dhrik M, Prasetya A. NPR. Kajian Pemilihan Obat Antihipertensi Pada Penderita Hipertensi Dengan Gagal Ginjal Kronis Yang Menjalani Hemodialisis. Acta Holistica Pharm. 2019;53(9):168999.

9. Martha K. Panduan Cerdas Mengatasi Hipertensi. Yogyakarta: Araska; 2012.

10. Nurrahmani U. Stop! Hipertensi. Jakarta: Familia; 2012.

11. Puspitariani M. Cara Mudah Mengatasi Tekanan Darah Tinggi. Yogyakarta: Aksara; 2011.

12. Polit FD, Beck CT. Nursing Researc, Geberating and Assesing Evidance for Nursing Practice. Philadephia: Lippincott Williams \& Wilkins; 2012 